\title{
Subscapular Artery
}

National Cancer Institute

\section{Source}

National Cancer Institute. Subscapular Artery. NCI Thesaurus. Code C33650.

An artery arising from the axillary artery with branches that supply the shoulder and

muscles of the scapular region. 